\title{
OS TRABALHADORES DO SISTEMA ÚNICO DE ASSISTÊNCIA SOCIAL (SUAS): UMA NOVA FORÇA SOCIAL EM QUESTÃO.
}

\author{
A THE WORKERS OF THE SINGLE SYSTEM OF SOCIAL ASSISTANCE (SUAS): A \\ NEW SOCIAL FORCE IN QUESTION.
}

\author{
G. L. A. da SILVA e E. ALGEBAILE1,* \\ 1 Universidade do Estado do Rio de Janeiro - UERJ, Programa de Pós-Graduação em Políticas \\ Públicas e Formação Humana - PPFH, Brasil.
}

\author{
ART I C LE INFO \\ Article history: \\ Received 2018-10-07 \\ Accepted 2018-12-20 \\ Available online 2018-12-21 \\ *Autor correspondente: \\ E-mail:gustavoleite1992@gmail.com
}

Palavras-chave: Estado. Assistência Social. Força social.

Keywords: State. Social Assistance. Social force

RESUMO. A implantação do Sistema Único de Assistência Social - SUAS, a partir da Política Nacional de Assistência Social - PNAS/2004, vem resultando em alterações significativas no campo social, inclusive nas relações de trabalho desse setor de atuação do Estado. A estrutura sistêmica desenhada possui bases institucionais e corpo técnico próprios, atuando em ampla escala no contexto das acentuadas desigualdades socioterritoriais do Brasil. Desta forma, tendo um aporte teórico de autores de perspectiva crítica, com destaque para Antônio Gramsci e análise de documentos normativos, este trabalho pretende trazer contribuições para o debate sobre as relações que se dão no âmbito dessa nova força social composta pelos trabalhadores do SUAS, que vem também se constituindo como uma importante força política em termos de defesa do Sistema.

ABSTRACT. The implementation of the Single Social Assistance System - SUAS, based on the National Social Assistance Policy - PNAS / 2004, has resulted in significant changes in the social field, including in the labor relations of this sector of State performance. The designed systemic structure has its own institutional bases and technical staff, acting on a large scale in the context of the marked socio-territorial inequalities in Brazil. In this way, with a theoretical contribution of authors from a critical perspective, with emphasis on Antônio Gramsci and analysis of normative documents, this paper intends to bring contributions to the debate about the relations that take place within the scope of this new social force composed by SUAS workers, which is also becoming an important political force in terms of defense of the System 


\section{Introdução}

A Constituição Federal de 1988 apresentou dispositivos importantes em termos de acesso aos diferentes direitos sociais no Brasil, como a elaboração do tripé social, constituído pela saúde, previdência social e assistência social. Nesse sentido, Yazbeck (2014) compreende a seguridade social ${ }^{1}$ como um dispositivo com ampla cobertura e que não depende do custeio individual direto dos cidadãos.

$\mathrm{Na}$ esteira dos avanços do texto constitucional, a Assistência Social passa a ser um direito e responsabilidade do Estado. Diante disso, em 1993 é promulgada a Lei Orgânica da Assistência Social -LOAS que, baseada na Constituição, traz importantes elementos balizadores em termos de organização do campo da assistência social brasileiro. No entanto, durante a década de 1990 o cenário passa a ser marcado por uma perspectiva de cortes de gastos sociais e pela "crescente subordinação das políticas sociais às políticas de ajuste da economia" (YASBECK, 2014, p.80)

Historicamente a assistência social é marcada por constantes disputas política e econômica, com isso, no início dos anos 2000, o conteúdo da LOAS se materializa e as políticas públicas desse campo de atuação estatal sofrem profundos redirecionamentos, com a organização da Política Nacional da Assistência Social - PNAS (2004).

Com isso, o presente artigo tem como objetivo manifesto discutir a implantação do Sistema Único da Assistência Social - SUAS e seus impactos nas relações de trabalho no campo da assistência, que vem demandando cada vez mais um corpo técnico profissional para atuar na gestão e execução das políticas do setor. Para isso, ressaltamos a importância de aprofundarmos nossa análise a luz dos conceitos de forças social e política do filósofo Antônio Gramsci².

A metodologia utilizada baseou-se em revisão bibliográfica e levantamento, catalogação e análise de documentos normativos. Autores de perspectiva crítica foram fundamentais para o aprofundamento do debate teórico sobre os elementos aqui apresentados e analisados.

A partir dos nexos estabelecidos entre as relações laborais que se dão com a implantação do SUAS e os referenciais teóricos utilizados, esse trabalho busca aprofundar a

\footnotetext{
${ }^{1}$ A Seguridade social brasileira pode ser compreendida, a partir do texto constitucional de 1988, como um amplo sistema que envolve os setores da saúde, previdência social e assistência social. Tratase de uma cobertura que não depende diretamente das contribuições individuais.

2 Gramsci foi condenado e encarcerado em 1926, em um processo de perseguição política por parte do governo italiano autoritário e fascista de Mussolini. No entanto, dentro da prisão, o filósofo registrou seus pensamentos nos chamados cadernos do cárcere e todos esses escritos significam a base do pensamento político gramsciano, pautada na análise de teor crítico sobre a realidade social e as relações de forças quem compõem tal realidade.
} 
análise sobre o campo da assistência social, apontando os limites, as potencialidades e contradições presentes nas mudanças promovidas ao longo dos anos 2000.

\section{O Estado brasileiro e o campo social - elementos históricos.}

A discussão sobre a Proteção Social no Brasil vem ganhando ênfase nos últimos anos devido ao intenso debate que está em curso sobre a forma de atuação do Estado no campo social, em um contexto de lutas sociais contra retrocesso no campo dos direitos.

Em termos históricos, a proteção social como âmbito de política pública no Brasil começa a ganhar maior expressão a partir do projeto de sociedade industrial no país, adensado no Governo do Presidente Getúlio Vargas (1930-1945), com a criação de órgãos gestores de políticas sociais e com a formulação de leis trabalhistas, com o objetivo de administrar de elementos sociais resultantes de uma sociedade capitalista desigual.

Durante o contexto de avanço da atuação estatal no campo social, começou-se a delimitar a concepção de cidadania, na qual Santos (1979) em suas formulações sobre essa questão, defendeu a ideia de "cidadania regulada", que se constitui como uma cidadania restrita, em que o sujeito é reconhecido como cidadão a partir de sua inserção em ocupações reconhecidas legalmente e a extensão dessa cidadania depende da regulamentação do Estado.

$\mathrm{Na}$ esteira dessa contextualização histórica, Yaszbek (2014) sinaliza que apesar de direitos ainda muito restritos, a garantia dos mesmos significou avanços importantes e as pressões realizadas por diferentes segmentos de trabalhadores foram fundamentais para a criação dos serviços sociais no país.

Entretanto, no período da Ditatura Civil-Militar instaurada com o golpe de 1964, a desigualdade social no Brasil se acentua, em um contexto no qual as restrições à participação política contêm em limites estreitos as lutas sociais referidas à direitos, resultando em uma expansão restrita da política social.

O início da década de 1960 acirra as contradições do capitalismo periférico trazendo consigo o golpe militar e a instalação do Estado autoritário. A opção pelo crescimento econômico acelerado, a partir de fontes de investimento externas, como base do desenvolvimento, abriu o país ao capital monopolista. O Estado amplia seu nível de intervenção, tornando-se o eixo político da recomposição do poder burguês, com a implantação de novas estratégias de desenvolvimento concentradoras de capital, intensificando o nível de exploração da classe operária. A desigualdade social se acentua em um clima repressivo e autoritário. (YASBECK, 2010, p. 82)

Com o processo de redemocratização do país, com forte apelo popular e com a reorganização das forças sociais em novas associações civis e políticas, a Constituição de 1988 sinaliza para a criação de um sistema de Proteção Social integrado e universal, através da concepção de seguridade social, formada pela saúde, assistência social e previdência. 
Nesse ambiente, ainda que com uma predominante presença de forças políticas conservadoras instituídas, a Lei Orgânica de Assistência Social (LOAS) é promulgada em 1993, garantindo a assistência social como direito do cidadão e dever do Estado, sendo definida como uma política de seguridade social não contributiva.

Apesar dos avanços na legislação em termos da atuação do Estado no campo social, principalmente a partir da Constituição Federal de 1988, o período desses dispositivos constitucionais foi marcado por um forte ideário neoliberal e com consequente regressão do Estado em termos de garantia dos direitos sociais. Anderson (1995) afirma que esse ideário se afirmou através de graves ataques aos direitos trabalhistas e aos movimentos sociais, com uma política econômica pautada em privatizações, redirecionamento das políticas sociais e cortes em investimentos públicos, ampliando com isso os espaços privados e diminuindo os públicos.

Diante desse cenário de regressão da atuação do Estado no campo social, nos anos 2000 vários governos progressistas foram eleitos na América Latina. No Brasil, a eleição do petista Luiz Inácio Lula da Silva em 2002 resultou em alterações na formulação e implantação das políticas sociais. É importante lembrar que ao longo da década de 1990, com atuação focalizada em determinados segmentos populacionais, inúmeros programas sociais foram criados e eram operacionalizados, na sua grande maioria, por equipes e espaços pertencentes a outras áreas de atuação estatal, como a educação.

Ao longo do Governo Lula, Aguiar (2015) lembra que a partir de 2004, com a implantação da Política Nacional de Assistência, o Sistema Único de Assistência Social (SUAS) começa a ganhar forma, a partir do delineamento de "procedimentos técnicos e políticos em termos de organização e prestação de medidas socioassitenciais" (AGUIAR,2015, p.6).

\section{A implantação do SUAS: o que muda para o trabalhador?}

A implantação de um Sistema único que organiza toda a atuação da Assistência Social no Brasil se constitui como um importante avanço em termos de políticas públicas e na garantia dos direitos sociais desenhados no texto constitucional de 1988, a partir da ideia de seguridade social.

No entanto, no contexto da década de 1990, as políticas de cunho neoliberal dos governos de Fernando Henrique Cardoso (1995/2002) fomentaram uma desorganização institucional do campo da Assistência Social, negando dispositivos importantes da LOAS de 1993. Para além da conjuntura relatada, Paiva (2006) aponta que historicamente as estruturas de poder político e econômico no Brasil estabelecem uma organização injusta de usufruto da riqueza coletivamente construída. 
Diante desses desafios complexos aqui mencionados, o SUAS se apresenta como uma forma de materializar "o conteúdo da LOAS, cumprindo no tempo histórico dessa política as exigências para a realização dos objetivos e resultados esperados que devem consagrar direitos de cidadania e inclusão social" (PNAS, 2004, p. 39).

O SUAS se constitui como um sistema descentralizado e participativo, envolvendo a União, estados e municípios, com ações voltadas para o enfrentamento das grandes e crescentes demandas sociais. Durante a análise da PNAS (2004), é possível observar também que essa organização sistêmica vem reforçando que a assistência social é um direito social e de responsabilidade do Estado.

$\mathrm{Na}$ esteira dessa caracterização geral, além do quadro profissional do Sistema envolver trabalhadores de diversas áreas, como advogados, psicólogos e assistentes sociais, a questão da intersetorialidade ${ }^{3}$ é central em termos de operacionalização do SUAS, principalmente entre os setores da saúde e educação.

Desta forma, Sposati (2001) afirma que a Assistência Social deve-se constituir com ações voltadas para a garantia de acesso aos direitos sociais universais por parte de diferentes segmentos da sociedade. Assim, o SUAS, a partir das Normas de Operacionalização Básica - NOB, deve ser implantado levando em conta os diferentes contextos socioterritoriais brasileiros, possuindo uma proximidade com as relações coletivas desenvolvidas em diferentes territórios, sendo preciso pensar a política pública a partir de revista à história, ao universo cultural e ao cotidiano da população presente em uma dada base territorial.

Para atender tais intenções relacionadas nos parágrafos anteriores, o SUAS passa a contar com uma arquitetura institucional e corpo técnico próprios, com atuação ampliada, presente nos diferentes territórios brasileiros e pautando-se na proximidade com os segmentos populacionais que são beneficiados das ações do sistema.

No âmbito da PNAS (Brasil, 2004), são criados os Centros de Referência de Assistência Social (CRAS), que são bases institucionais constituídas com a função de executar serviços de proteção social básica.

De acordo com o Ministério de Desenvolvimento Social, os CRAS são definidos como:

uma unidade pública estatal descentralizada da Política Nacional de Assistência Social (PNAS). O Cras atua como a principal porta de entrada do Sistema Único de Assistência Social (Suas), dada sua capilaridade nos territórios e é responsável pela organização e oferta de serviços da Proteção Social Básica nas áreas de vulnerabilidade e risco social. (Apresentação institucional disponível no site do MDS)

\footnotetext{
${ }^{3} \mathrm{~A}$ ideia de intersetorialiadade não é apresentada como foco de análise desse trabalho, no entanto, de forma genérica, entendemos, a partir de Junqueira (1997), que trabalhar na perspectiva intersetorial significa uma nova maneira de planejar, executar e controlar a prestação dos diferentes serviços, alterando todas as articulações realizadas pelos diversos segmentos governamentais, abrindo espaço para estratégias de gestão integrada.
} 
No mesmo documento, encontra-se a seguinte definição do CREAS:

O Centro de Referência Especializado de Assistência Social (Creas) configura-se como uma unidade pública e estatal, que oferta serviços especializados e continuados a famílias e indivíduos em situação de ameaça ou violação de direitos (violência física, psicológica, sexual, tráfico de pessoas, cumprimento de medidas socioeducativas em meio aberto, etc.). (Apresentação institucional disponível no site do MDS)

É importante destacar que as bases institucionais conceituadas acima compõem uma malha institucional presente em maior escala no território brasileiro. Segundo dados do Censo - SUAS 2016, levantamento realizado anualmente pelo Governo Federal, há no país 8.240 CRAS e 2.521 CREAS.

\subsection{Os trabalhadores do SUAS: uma nova força social?}

Historicamente a assistência social no Brasil é ligada a ideia do assistencialismo e da filantropia, diante disso a ação assistencial não é vista como uma ação profissional, que acaba trazendo limites a esse campo laboral.

Yasbeck (2010) afirma que as políticas sociais no contexto de hegemonia neoliberal assumem características seletivas e filantrópicas, resultando na desmontagem e retração dos direitos e impactando no fortalecimento da ideia de desprofissionalização do campo da assistência social, além da dispersão de seus profissionais no interior das relações de trabalho.

Aguiar (2015) sinaliza que a PNAS (2004) é lançada com importantes elementos em termos de garantia de acesso por diversos segmentos sociais a direitos básicos universais. No entanto, a desprofissionalização histórica dos trabalhadores da assistência social se constitui como um desafio complexo na implantação do SUAS no Brasil.

$\mathrm{Na}$ esteira dessa discussão, Aguiar (2015) diz que em 2006, no contexto de aperfeiçoamento da implantação do SUAS, é aprovada a NOB - Recursos Humanos. Esse conjunto de normas é importante pois

estabelece parâmetros gerais para a gestão do trabalho a ser implementada na área da assistência social, englobando todos os trabalhadores do SUAS, órgãos gestores e executores de ações, serviços, programas, projetos e benefícios da assistência social. (AGUIAR, 2015, p.07)

A NOB - RH organiza a operacionalização do SUAS a partir das chamadas equipes de referência, que são servidores que atuam na organização e oferta das ações de proteção social básica e especial dentro das bases institucionais do Sistema. 
Quadro 01 -Organização das equipes dos CRAS a partir do porte dos municípios.

\begin{tabular}{|c|c|c|}
\hline Pequeno Porte I & Pequeno Porte II & $\begin{array}{c}\text { Médio, Grande, Metrópole e } \\
\text { DF. }\end{array}$ \\
\hline $\begin{array}{c}\text { Até } 2.500 \text { famílias } \\
\text { referenciadas }\end{array}$ & $\begin{array}{c}\text { Até 3.500 famílias } \\
\text { referenciadas }\end{array}$ & $\begin{array}{c}\text { A cada 5.000 família } \\
\text { referenciadas. }\end{array}$ \\
\hline $\begin{array}{c}\text { 2 técnicos de nível superior, } \\
\text { assistente um profissional } \\
\text { preferencial e outro }\end{array}$ & $\begin{array}{c}03 \text { técnicos de nível } \\
\text { superior, sendo dois } \\
\text { profissionais assistentes } \\
\text { sociais e preferencialmente } \\
\text { um psicólogo. }\end{array}$ & $\begin{array}{c}04 \text { técnicos de nível } \\
\text { superior, sendo dois } \\
\text { profissionais assistentes } \\
\text { sociais, um psicólogo e um } \\
\text { profissional que compõe o } \\
\text { SUAS }\end{array}$ \\
\hline 2 técnicos de nível médio. & $\begin{array}{c}\text { 3 técnicos nível médio. } \\
\text { Fonte: NOB/RH - SUAS (2006) }\end{array}$ \\
\hline
\end{tabular}

\title{
Quadro 02 - Organização das equipes dos CREAS
}

\begin{tabular}{|c|c|}
\hline Municípios de pequeno e médio porte & $\begin{array}{l}\text { Municípios de Grande porte, metrópoles e } \\
\text { Estados com Serviços Regionais. }\end{array}$ \\
\hline $\begin{array}{c}\text { Capacidade de atendimento de } 50 \\
\text { pessoas/ individuais }\end{array}$ & $\begin{array}{c}\text { Capacidade de atendimento de } 80 \\
\text { pessoas/ individuais }\end{array}$ \\
\hline 01 coordenador & 1 coordenador \\
\hline 01 assistente social & 2 assistentes sociais \\
\hline 01 psicólogo & 2 psicólogos \\
\hline 01 advogado & 1 advogado \\
\hline $\begin{array}{c}02 \text { profissionais de nível superior ou médio } \\
\text { (abordagem dos usuários) }\end{array}$ & $\begin{array}{l}4 \text { profissionais de nível superior ou médio } \\
\text { (abordagem dos usuários) }\end{array}$ \\
\hline 01 auxiliar administrativo & 2 auxiliares administrativos \\
\hline
\end{tabular}

Fonte: NOB/RH - SUAS (2006)

Diante desse conjunto de informações apresentadas, é possível trabalhar com a ideia de que a implantação do SUAS vem exigindo da gestão do Sistema a ampliação dos quadros de trabalhadores para compor as esquipes das diferentes esferas governamentais, principalmente as que atuam nas bases institucionais próximas aos beneficiários das ações assistenciais.

\begin{abstract}
A implantação do Suas exige novas formas de regulação, organização e gestão do trabalho e, certamente, a ampliação do número de trabalhadores com estabilidade funcional é condição essencial, ao lado de processos continuados de formação e qualificação, a partir do ingresso via concurso público, definição de cargos e carreiras e de processos de avaliação e progressão, caracterização de perfis das equipes e dos serviços, além de remuneração compatível e segurança no trabalho. (RAICHELIS, 2010, p. 761)
\end{abstract}

Nesse sentido, é perceptível observar, em termos normativos, a organização profissional de um campo da ação do estado marcado pela desprofissionalização e dispersão histórica de seus quadros.

Com o objetivo de aprofundar a análise, buscamos nas obras de Antônio Gramsci, importante filósofo italiano de inegável atuação política no contexto dominado pelo fascismo, 
conceitos fundamentais para refletir sobre as novas relações de trabalho que estão em curso com a implantação do SUAS.

Em face aos inúmeros conceitos elaborados por Gramsci, os de forças social e política se constituem como importantes elementos na análise do processo que vem sendo descrito com a implantação do SUAS, marcado por avanços, limites e contradições.

A luz da análise gramsciana, força social está ligada à

[...] estrutura, objetiva, independentes da vontade dos homens, que pode ser mensurada com os sistemas de ciências exatas ou físicas. Com base no grau de desenvolvimento das forças materiais de produção, têm-se os agrupamentos sociais, cada um dos quais representa uma função e ocupa uma posição determinada na própria produção. (GRAMSCI, 2012, p.40)

Diante da conceituação de força social, Gramsci (2012) sinaliza que essa força é uma realidade rebelde, que vai se constituindo a partir do desenvolvimento das forças materiais de produção. Nesse sentido, a organização desenhada para os profissionais do SUAS, anteriormente dispersos com a ausência de uma estrutura sistêmica, pode-se apresentar como uma nova força social, resultante de um histórico processo de lutas entre forças dominantes instituídas e outros grupos sociais

Essa nova força social composta pelos trabalhadores do SUAS vem apresentando grande potencial para se constituir também como uma importante força política, a partir da organização de espaços de reflexão e discussão coletiva, pautando-se na atuação política em defesa do fortalecimento do SUAS no âmbito nacional.

Em relação as forças políticas, Gramsci (2012, p.41) aponta que são forças com um determinado grau de

[...] homogeneidade, de autoconsciência e de organização alcançado pelos vários grupos sociais. Este momento, por sua vez, pode ser analisado e diferenciado em vários graus, que correspondem aos diversos momentos de consciência política e coletiva, tal como se manifestaram na história até agora.

Os profissionais das áreas que atualmente compõem o SUAS contam com representações políticas históricas e consolidadas na luta por melhores condições de trabalho. No entanto, com esses trabalhadores organizados dentro de uma estrutura pública sistêmica, essa nova força social começa, a partir de 2009, a organizar movimentos coletivos democráticos de enfrentamento político. 


\subsection{Limites e potencialidades da nova força social.}

Podem ser submetidos artigos e resenhas nos idiomas português, inglês e espanhol, que, se aprovados, serão publicados na língua original. Os custos com revisão de artigos em inglês e espanhol deverão ser cobertos pelo(a) autor(a). A REVES indicará os profissionais habilitados. As submissões poderão receber pareceres nas três línguas. Ao submeter o artigo, o(a) autor(a) concorda em receber pareceres nas três línguas. Os trabalhadores do SUAS, desde a implantação do Sistema, vêm se organizando a partir de movimentos políticos com a intenção de colocar em pauta as demandas crescentes, visando fortalecer a atuação dessa nova arquitetura institucional pública em expansão.

Durante a VII Conferência Nacional de Assistência Social, em sessão plenária nacional dos/as trabalhadores/as do SUAS, em 2009, foi concebido o Fórum Nacional dos Trabalhadores/ as do Sistema Único da Assistência Social (FNTSUAS) ${ }^{4}$, que atualmente se constitui como um espaço coletivo de organização política de maior expressão em termos de escala do campo dos trabalhadores do Sistema.

Durante o contexto de criação do Fórum, foi lançada uma carta que estabelece as diretrizes de atuação do FNTSUAS que possui um caráter permanente, formado por meio de

representações de entidades nacionais (de natureza sindical, acadêmicacientifica, de fiscalização do exercício profissional, de representação/categoria profissional) e de representações dos Fóruns estaduais dos Trabalhadores do SUAS - FETSUASs" (Carta Institucional com apresentação das diretrizes de atuação do FNTSUAS).

O FNTSUAS reúne entidades políticas nacionais, como a Central Única dos Trabalhadores - CUT; Central dos Trabalhadores e Trabalhadoras do Brasil - CTB; Confederação Nacional dos Trabalhadores da Seguridade Social - CNTSS; Federação Nacional dos Assistentes Sociais - FNAS e a Federação Nacional dos Psicólogos FENAPSI. Além disso, estabelece importantes objetivos voltados paras as relações de trabalho no âmbito do Sistema, como:

a) manter um diálogo junto aos Conselhos Nacional, estaduais e municipais de Assistência Social;

b) construir de forma permanente um canal de comunicação com a Comissão Intergestora Tripartite (CIT), autoridades públicas e gestores das diferentes esferas governamentais;

c) estabelecer permanentes diálogos com entidades e fóruns estaduais, com o objetivo de construir um conteúdo programático em comum;

4 Sinalizamos que o FNTSUAS é utilizado nesse texto como uma organização concreta de representação política em desenvolvimento composta por trabalhadores do SUAS de múltiplas áreas e diversos níveis de escolaridade, com atuação em escala nacional. É válido ressaltar também que trata-se de um olhar sobre o Fórum que se enquadra dentro dos limites de uma pesquisa documental. 
d) promover e estimular a formação política e acadêmica dos trabalhadores/as do SUAS;

e) fomentar o debate sobre as condições de trabalho no cotidiano do SUAS.

No caminhar da análise, a partir das informações aqui colocadas sobre a organização do FNTSUAS, sinalizamos que os trabalhadores do SUAS começam a ter uma atuação política com pautas que circunscrevem as relações laborais que se dão no cotidiano da Assistência Social. O Fórum vem intensificando campanhas e encontros, de cunho político e acadêmico, para pensar e debater os desafios do SUAS, que na atual conjuntura brasileira, vem sendo atacado por previsões de grandes cortes orçamentários.

Retornando a Gramsci (2012), apontamos que as forças políticas possuem um determinado grau de autoconsciência e organização, se apresentando como forças programáticas e que trazem elementos de intencionalidade. Assim, a organização política dos trabalhadores em um Fórum Nacional apresenta-se como uma força política em formação, com potencial de tencionar a agenda pública em relação ao campo da Assistência Social.

$\mathrm{Na}$ esteira dessa questão, Aguiar (2010) faz importantes apontamentos sobre as relações de trabalho que se dão no âmbito do SUAS, sinalizando que os trabalhadores ganharam um papel relevante com a operacionalização do Sistema, no entanto, em um país marcado por práticas que se constituem como limites históricos da ação política, juntamente com o não rompimento de um ideário neoliberal, reforçado no cenário atual, muitos trabalhadores do SUAS acabam sendo inseridos pela via da precarização, resultando em um possível enfraquecimento da Força Social composta por esses profissionais e causando instabilidades na oferta dos serviços socioassistenciais.

Para ser executada, a referida política passou a requisitar em seus quadros, profissionais tecnicamente qualificados, sendo este um grande desafio a ser enfrentado, uma vez que: a) historicamente os gestores não se preocupavam em formar quadros técnicos para operacionalização da assistência social; b) forte participação do voluntariado; c) presença do primeiro damismo; d) cultura do improviso; e) ser esta uma política financeiramente pouco atrativa aos trabalhadores; f) ausência na formação acadêmica desta temática (AGUIAR, p.10, 2015)

Com objetivo traçar um quadro das relações de trabalhos desenvolvidas no Sistema, consultamos o Censo SUAS - 2016, onde é possível verificar os tipos de vínculos que marcam a composição do quadro profissional presente nos CRAS e CREAS. 
Tabela 01 - Tipos de vínculos dos trabalhadores do SUAS

\begin{tabular}{|c|c|c|}
\hline Tipo de Vínculo & $\begin{array}{c}\text { Quantidade de trabalhadores- } \\
\text { CRAS }\end{array}$ & $\begin{array}{c}\text { Quantidade de Trabalhadores - } \\
\text { CREAS }\end{array}$ \\
\hline Estatutário & 30.507 & 2.521 \\
\hline $\begin{array}{c}\text { Emprego público - } \\
\text { CLT }\end{array}$ & 5.842 & 1559 \\
\hline Comissionado & 8.380 & 5.867 \\
\hline Contrato Temporário & 27.543 & 1.235 \\
\hline Terceirizados & 9.876 & 2.880 \\
\hline $\begin{array}{c}\text { Outros vínculos não } \\
\text { permanentes }\end{array}$ & 6.890 & 22.680 \\
\hline TOTAL & 89.038 & \\
\hline
\end{tabular}

Fonte: CENSO SUAS - 2016

Os dados apresentados elucidam que há um grande quantitativo de vínculos considerados não permanentes e/ou indiretos, principalmente via contratos temporários e terceirizações. Essa questão se mostra contraditória em relação ao que é colocado no texto da NOB - RH/SUAS, pois segundo as normas, os profissionais das equipes que compõem as bases institucionais do Sistema devem ser servidores efetivos.

Para além disso, os dados atuais reforçam a tendência sinalizada por Silveira (2011) no início da implantação do SUAS, em que nos primeiros anos de operacionalização, entre 2005 e 2009, a partir de consulta ao MUNIC/IBGE (2010), houve aumentos de 30,7\% de trabalhadores permanentes e $73,1 \%$ sem vínculo permanente, ou seja, a maioria dos novos trabalhadores vêm se inserindo via contratos precarizados.

Desta forma, mesmo com avanços da última década na área da Assistência Social, o SUAS vem sendo marcado por uma "ausência e/ou insuficiência de admissão por concursos públicos, com número significativo de profissionais contratados por tempo determinado e com baixos salários" (AGUIAR, 11, 2010).

Nesse sentido, podemos relacionar algumas questões importantes e que trazem elementos resultantes da intensificação da precarização das condições de trabalho, como a: a) produção de uma vulnerabilidade estrutural com a construção de formas precárias de inserção laboral;

b) produção de desvalorização e intensificação do descarte das pessoas, fragilizando as identidades individual e coletiva;

c) ampliação de ritmos de trabalho e da rotatividade de trabalhadores, afetando diretamente a continuidade, o padrão dos serviços prestados pelas bases institucionais do Sistema e o potencial de mobilização dessa força social;

\footnotetext{
${ }^{5}$ Segundo o Censo Suas 2016, a categoria "outros vínculos" referência trabalhadores cooperativados e voluntários.
} 
d) fragilização da representação política dos trabalhadores.

Dentro das consequências geradas com a precarização das relações de trabalho no SUAS, chamamos a atenção para a questão da representação política, elemento central na análise desenvolvida nesse trabalho. Pois segundo Silveira (2011), todo esse quadro amplia a fragilidade da força política dos trabalhadores, pois gera um ambiente de instabilidade e competição entre os profissionais

A partir do quadro apontado, sinalizamos que os trabalhadores do SUAS, dentro de seus espaços coletivos políticos, constroem pautas voltadas para o fortalecimento das condições de trabalho no Sistema, ganhando destaque na esfera pública temas como:

a) a realização de concursos públicos para a admissão de servidores, ampliando o quadro de trabalhadores permanentes;

b) a implantação ou adequação dos Planos de Cargos e Carreiras, garantindo condições de permanência aos trabalhadores;

c) a implantação de uma política nacional permanente voltada para a capacitação de servidores, estando relacionada com os Planos de Capacitação dos entes federados; d) a criação de mecanismos voltados para a garantia de condições étnicas e técnicas de trabalho, bem como fortalecer a luta pelo aumento orçamentário para a manutenção e ampliação do Sistema;

e) a criação de um canal permanente de negociação nas diferentes esferas governamentais, com acompanhamento da efetivação dos princípios e das diretrizes oriundas do Governo Central.

Diante das questões apresentadas nesse trabalho, observamos os avanços constituídos com a operacionalização do SUAS e a construção de uma força social que vem tendo uma importante atuação política, entretanto o caminho à ser trilhado com o objetivo de vencer as limitações que vêm marcando a implantação do Sistema da Assistência Social é longo, exigindo permanentes mobilizações.

\section{Considerações finais}

A nova força social constituída com a organização do SUAS e seus avanços em termos de força política, são elementos importantes para o tensionamento da agenda pública, principalmente no contexto atual marcado por graves ataques aos direitos sociais.

A assistência social expandiu-se em termos de equipamentos públicos e contratação de profissionais. No entanto, para efetivar a implantação do SUAS é preciso construir condições com o objetivo de superar a lógica da precarização e da minimização orçamentária, para tal, a mobilização política é fundamental.

Finalizamos, sinalizando que esse trabalho, dentro dos limites de uma pesquisa bibliográfica e documental, trouxe elementos do novo quadro do campo da assistência social 
no Brasil e seus impactos para os profissionais do setor. Assim, diante do contexto atual de organização política dos trabalhadores do SUAS e ao mesmo tempo de graves retrocessos na atuação estatal no campo social, é preciso fortalecer a luta pelo projeto de democratização do Estado, com a intenção de superar a retração das forças políticas e fortalecer a coletividade.

\section{Referências}

AGUIAR, E. L.. As transformações no mundo do trabalho e seus impactos para o trabalhador do Sistema Único de Assistência Social. In: Políticas Públicas Para Além da Crise Global: Experiências e Antecipações Concretas, 2015. Anais da VII Jornada Internacional Políticas Públicas, São Luís: UFMA, 2015.

ALGEBAILE, E.; SILVA, G. L. A.; FAGUNDES, T.. Referenciamento Territorial de Políticas Sociais e Reconfiguração do Sistema Educativo no Brasil. In: XIII Coloquio Internacional de Geocritica - El control del espacio y los espacios de control. Barcelona. Anais do XIII Colóquio de Geografia Critica 2014.

ANDERSON, Perry. Balanço do Neoliberalismo. In SADER, Emir (org); GENTILI, Pablo (org). Pós-neoliberalismo: as políticas sociais e o Estado democrático. Rio de Janeiro: Paz e Terra, 1995, p. 9-23.

BRASIL. Constituição Federal de 1988. Promulgada em 5 de outubro de 1988. Disponível em <http://www.planalto.gov.br/ccivil 03/constituicao/constituição.htm>. Acesso em: $25 / 11 / 2017$

BRASIL. Ministério da Previdência Social. Lei n. 8.742, de 7 de dezembro de 1993. Dispõe Sobre a Organização da Assistência Social e dá outras providências. Brasília, 1993.

BRASIL. Ministério do Desenvolvimento Social e Combate à Fome e a Miséria (MDS), Política Nacional de Assistência Social/ Sistema Único de Assistência Social-SUAS. Brasília, DF: Secretaria Nacional de Assistência Social/MDS, 2005.

BRASIL, Ministério do Desenvolvimento Social e Combate à Fome. Norma Operacional Básica de Recursos Humanos NOB/RH. Brasília, 2006.

FÓRUM NACIONAL DOS TRABALHADORES DA ASSISTÊNCIA SOCIAL. Regimento Interno do FNTSUAS. Disponível em <http://fntsuas.blogspot.com.br/p/carta-de-principios-eregimento-interno.html >. Acesso em: 01/12/2017.

GRAMSCI, A. Cadernos do cárcere. Volume 3. Edição e Tradução de Carlos Nelson Coutinho; Co-edição de Luiz Sérgio Henriques e Marco Aurélio Nogueira. 5ª ed. Rio de Janeiro: Editora Civilização Brasileira, 2012.

JUNQUEIRA, Luciano A. Prates. Novas formas de gestão na saúde: descentralização e intersetorialidade. Rev. Saúde e Sociedade, v. 6, n. 2, p. 31-46, 1997. 
MONNERAT, Giselle Lavinas; SOUZA, Rosimary Gonçalves de. Da Seguridade Social à intersetorialidade: reflexões sobre a integração das políticas sociais no Brasil. Revista Katálysis (Impresso), Florianópolis, v. 14, n. 1, p. 41-49, jan./jun. 2011.

PAIVA, Beatriz Augusto de. O SUAS e os direitos socioassistenciais: a universalização em debate. In: Revista Serviço Social e Sociedade, n. 87, p. 05-24, 2006.

RAICHELIS, Raquel. Intervenção profissional do assistente social e as condições de trabalho no SUAS. In: Revista Serviço Social \& Sociedade, São Paulo, n. 104, p. 750-772, 2010.

RAICHELIS, Raquel. O Trabalho e os Trabalhadores do SUAS: o enfrentamento necessário na assistência social. In: José Crus. (Org.). Gestão do Trabalho no Âmbito do SUAS: uma contribuição necessária para ressignificar as ofertas e consolidar o direito socioassistencial. $1^{a}$ ed.Brasília, DF: Ministério do Desenvolvimento Social e Combate à Fome - MDS, 2011, v. 1, p. 41-66.

SANTOS, Wanderley Guilherme. Cidadania e justiça: a política social na ordem Brasileira. Rio de Janeiro: Campus, 1987.

SILVEIRA, J. I.. Gestão do Trabalho: concepção e significado para o SUAS. In: José Crus. (Org.). Gestão do Trabalho no âmbito do SUAS: uma contribuição necessária para ressignificar as ofertas e consolidar o direito socioassistencial. $1^{\underline{a}}$ ed.Brasília: Ministério do Desenvolvimento Social e Combate à Fome - MDS, 2011, v.01, p. 09-38.

SPOSATI, A. Desafios para fazer avançar a política de assistência social no Brasil.In: Revista Serviço Social e Sociedade, São Paulo, n. 68, p. 54-82, 2001

YAZBEK, Maria Carmelita. Sistemas de proteção social, intersetorialidade e integração de políticas. In: ALMEIDA, Ney Luiz Teixeira de (Org.); MONNERAT, Giselle (Org.); SOUZA, R. G. (Org.) . A intersetorialidade na agenda das políticas sociais. 1a. ed. São Paulo: Papel Social, p. 77-104, 2014. 